\title{
Student views of instructor-student rapport in the college classroom
}

\begin{abstract}
Nathan G. Webb ${ }^{1}$ \& Laura Obrycki Barrett ${ }^{2}$
Abstract: Building upon past research on the positive learning outcomes associated with rapport building in the classroom, this study examines the specific behaviors instructors utilize in college classrooms to build rapport with undergraduate students. Participants $(N=230)$ answered open-ended survey questions about their instructors' rapport-building behaviors. A total of 514 behaviors described as rapport building were categorized into five themes: attentive behaviors, common grounding behaviors, courteous behaviors, connecting behavior, and information sharing behaviors.
\end{abstract}

Keywords: rapport, instructor-student relationships, learning outcomes, instructor behaviors

\section{Introduction}

Interpersonal communication is everywhere, and the college classroom is no exception. Dobransky and Fymier (2004) support this assertion by claiming that instructor-student relationships in the classroom are often interpersonal in nature. Many researchers claim that interpersonal relationship building is necessary for the effective transmission of ideas between instructors and students to occur. For example, Worley, Titsworth, Worley, and Cornett-Devito (2007) state that instructor-student relationships are not only important for effective communication to take place, but are vital for student learning. Tsui (1996) also notes, "establishing a good relationship with students is extremely important in creating a conducive learning atmosphere in the classroom" (p. 164). This emphasis on building relationships with students begs the question, how does an instructor build good relationships?

Extensive research has examined this question by studying instructor-student relationships and the learning outcomes associated with certain behaviors. A wide variety of behaviors are associated with positive classroom outcomes, including: self-disclosure (Mazer, Murphy, \& Simonds, 2007), humor (Gorham \& Christophel, 1990), nonverbal immediacy, (Frymier \& Houser, 2000), clarity (Chesebro \& McCroskey, 1998), fairness (Faranda \& Clark, 2004), and rapport building (Frisby \& Martin, 2010).

Building rapport, as a relationship variable, has only recently received scholarly attention in instructional settings (e.g., Catt, Miller, \& Schallenkamp, 2007; Frisby \& Martin, 2010; Frisby \& Myers, 2008; Nguyen, 2007). Frisby and Myers (2008) support this claim and assert that instructor-student rapport is an understudied phenomenon. Recent research indicated that rapport building is indeed an important variable for student learning, but the specific behaviors that students view as rapport building have not been examined in detail. Frisby and Martin (2010) state, "Thus far, rapport seems to be a positive interpersonal construct utilized in the instructional setting. However, it remains unknown exactly which instructor behaviors lead to building rapport with students" (p. 160). The current study qualitatively examines the specific instructor behaviors that students define as rapport building in the college classroom. By providing

\footnotetext{
${ }^{1}$ Department of Communication Studies, Belmont University, Nashville, TN, nathan.webb@belmont.edu

${ }^{2}$ Department of Communication Studies, University of Kansas, Lawrence, KS, lobarrett@ku.edu
} 
concrete examples of how students describe rapport building in the college classroom, this study provides practical advice for both new and seasoned instructors looking to enhance the learning environment in their classrooms.

This study is situated in the literature on rapport building, and adds a qualitative component to the current understanding of rapport as potentially beneficial in the college classroom. A review of past research on rapport building frames the current study of student views of rapport-building behaviors in the college classroom.

\section{Literature Review}

Rapport is a behavior that is defined and operationalized in different ways. Faranda and Clark (2004) define rapport as building a relationship based on mutual trust and harmony, and Nadler (2007) explains rapport as positive mutual attention marked by affinity and harmony. Gremler and Gwinner (2000) explain rapport building in two different, but related, ways: a personal connection and an enjoyable interaction.

\section{Rapport Research in Organizational Contexts}

Recent research on instructor-student rapport grew out of past examinations of rapport building in various organizational contexts such as corporate negotiation (Nadler, 2007) and retail employee-customer relationships (Gremler \& Gwinner, 2008). This research demonstrates a variety of behaviors that contribute to building rapport between individuals. Research focusing on corporate negotiation (Nadler, 2007) suggests that rapport is built through nonverbal behaviors such as facing the other person, leaning forward, making eye contact, and mimicry of the other person through posture, facial expressions, tone of voice, and mannerisms. Nadler's (2007) research also reaches beyond the scope of nonverbal communication, and asserts that one can build rapport by conducting face-to-face meetings, chatting informally before conducting business, and through self-disclosure.

Gremler and Gwinner (2008), in a study on rapport building tactics used by retail employees with customers, found five significant themes of rapport building behaviors. These behaviors included uncommonly attentive behavior, common grounding behavior, courteous behavior, connecting behavior, and information sharing behavior. Uncommonly attentive behaviors refer to behaviors that were viewed as above-and-beyond by the customer. Common grounding behaviors refer to attempts by the employee to show what he/she has in common with the customer. Courteous behavior is exemplified through considerate behaviors that appear to have the best interests of the customer in mind. Connecting behavior is explained as an employees' attempt to form a bond with the customer. Last, information-sharing behaviors refer to an employee sharing information with the customer that is perceived to make the customers' experience better.

\section{Effects of Building Rapport in the Classroom}

Rapport building between instructors and students is increasingly viewed as essential to a positive classroom experience. Faranda and Clark (2004) list rapport as one of the top six attributes that students believe are present in good instructors, and early research on rapport 
building (i.e. McLaughlin \& Erickson, 1981) suggested that rapport is crucial characteristic of being an "ideal" instructor.

Schrodt and Witt (2006) explain the potential benefits of rapport building, stating, "few can deny the fundamental importance of instructors establishing...rapport with students at the beginning of a new semester" (p. 3). Frisby and Myers (2008), drawing from research by Roach, Cornett-Devito, and Devito (2005) succinctly explain the potential benefits of rapport building in a classroom setting:

Intuitively, an instructor who maintains positive rapport with students would also achieve a sense of liking from them, increase students' state motivation, and enhance students' satisfaction, in part because student's feelings of liking for instructors often evolves into liking for the course and increased learning. (p. 28)

The effects of rapport building between instructors and students align with assumptions of the Affective Learning Model (ALM) (Rodriguez, Plax, \& Kearney, 1996). The ALM posits that favorable instructor behaviors are essential to building relationships between students and instructors, which can help create positive student affect toward both the instructor and the class, which in turn may improve cognitive learning. Affective learning refers to students' feelings about course content, about enrolling in another course with similar content, and about the course instructor (Frisby \& Martin, 2010). Cognitive learning refers to the process of a student gaining knowledge related to course material and developing intellectual skills (Bloom \& Krathwohl, 1956). The ALM has been utilized by Communication Studies scholars to examine how instructor behaviors such as immediacy (Rodriguez et al., 1996) and rapport building (Frisby \& Martin, 2010) can increase students' affective and cognitive learning.

Although the benefits of classroom rapport have been demonstrated, an in-depth look at how exactly to build rapport in the classroom is missing from the research (Frisby \& Martin, 2010). Since the ALM demonstrates that instructor behaviors can enhance cognitive learning, an understanding of the specific ways that rapport can be built in the classroom is warranted. By analyzing student reports of behaviors that build rapport in the classroom, this study contributes to the literature on rapport building by providing specific behaviors that instructors can use to enhance the classroom environment, which in turn may lead to increases in student learning.

\section{Research Question}

Due to the perceived similarities in interpersonal communication between the employeecustomer relationship and the instructor-student relationship in the classroom setting, the theoretical framework provided by Gremler and Gwinner (2008) guides the data analysis in the current study. Viewing college students as customers is a widely discussed and highly debated topic in higher education (George, 2007). However, this research project is not meant to be part of that debate. Instead, this project is designed to focus on how interpersonal communication behaviors can effectively be utilized in the classroom. Specifically, this paper seeks to better understand the rapport-building behaviors that instructors can use to build positive relationships with college students.

Consequently, the following research question was posed:

RQ: What specific instructor behaviors do students view as building rapport in the classroom? 


\section{Method}

\section{Methodological Framework}

Following the lead of Gremler and Gwinner (2008), the Critical Incident Technique (CIT) was used to guide the research methodology for the current study. CIT is a qualitative research method developed by Flanagan $(1949 ; 1954)$ that has been used in a variety of social scientific research scenarios. Hughes (2007) describes the CIT method as follows:

As its name suggests, critical incident technique involves the study of critical incidents or significant instances of a specific activity - as experienced or observed by the research participants. Detailed analysis of critical incidents enables researchers to identify similarities, differences and patterns and to seek insight into how and why people engage in the activity. (p. 49)

Findings from the CIT method are typically used to support practical outcomes, such as improving customer relations in the service industry (Gremler, 2004) or refining pedagogical effectiveness with students (Kain, 1997). Drawing from Stephen Brookfield's (1995) widely cited research on critical teaching, Philan (2012) asserts that the use of critical incidents are regularly "deployed in part to provide access to students' view of teaching practice" (p. 32).

\section{Instruments}

To answer the above research question, college students in a general education public speaking class were recruited to participate in a self-administered survey. The survey took approximately 20-30 minutes to complete and students completed the survey online at a convenient time outside of class. The survey included both open-ended and close-ended questions, however only the open-ended questions were examined for this study. The survey began with basic demographic questions and then offered six open-ended questions on rapport building. Specifically, students were asked to describe how their public speaking instructor built rapport with them in their public speaking classroom. For example, students were asked to respond to the following open-ended question: "What behaviors do you see from your instructor in the classroom that makes you feel that he/she has built rapport with you?" A brief definition of rapport was provided in the survey to ensure that participants were familiar with the concept.

\section{Participants}

Participants were recruited from public speaking classes at a large Midwestern university and received class credit for participating. All participants were enrolled in a public speaking class taught by a graduate teaching assistant or part-time lecturer. A total of 230 participants completed the survey, and the sample was evenly split between males and females (47\% male, $\mathrm{n}=108 ; 53 \%$ female, $\mathrm{n}=122)$. The majority of the sample was freshman $(57 \%, \mathrm{n}=132)$, with all undergraduate class levels represented ( $27 \%$ sophomores, $n=62 ; 10 \%$ juniors, $n=24 ; 6 \%$ seniors, $\mathrm{n}=13$ ). The study included students in a variety of academic majors, as the class was a general education option at the university. Participants completed this survey beginning at the semester's midterm, which allowed students sufficient time to examine how their instructor built rapport in the classroom. 


\section{Data Analysis}

All information that could identify student participants or public speaking instructors was removed from the survey responses prior to beginning data analysis. Since both of the authors were teaching public speaking courses during the semester the survey was completed, and knew many of the other instructors, removing the identifying information maintained the confidentiality of participants and the instructors they referenced. Reponses to the open-ended questions regarding behaviors that build rapport in the public classroom were first coded independently by both authors using the themes provided by Gremler and Gwinner (2008). The authors interpreted units of analysis as words, sentence fragments, complete sentences, or multiple sentence responses, allowing the flexibility to interpret the participant responses. In order to adapt the themes from an employee-customer relationship to an instructor-student relationship, the authors met several times to discuss coding discrepancies and to create new guidelines for how to code specific behaviors. After several rounds of coding and discussion, the authors determined that all five themes were well adapted to categorize behaviors in the instructor-student relationship, and each coded half of the data set to obtain final category counts discussed below.

\section{Results}

A total of 514 behaviors described as building instructor-student rapport were categorized into the five themes provided by Gremler and Gwinner's (2008) study. The five themes used to code the data were: uncommonly attentive behaviors, common grounding behaviors, courteous behaviors, connecting behavior, and information sharing behavior. The current data set included 133 (25.9\%) uncommonly attentive behaviors; 122 (23.7\%) connecting behaviors; 106 (20.6\%) information-sharing behaviors; 97 (18.9\%) courteous behaviors; 56 (10.9\%) common grounding behaviors. Many student responses included reference to more than one type of rapport building behavior, indicating the dynamic nature of the construct. Although not prompted to do so, several students included behaviors that hindered the development of rapport in the classroom; these examples are discussed below as they provide examples of behaviors to avoid in the classroom. Specifics behaviors found in each category and examples from student responses are discussed below.

\section{Uncommonly Attentive Behaviors}

Uncommonly attentive instructor behaviors are demonstrated when instructors offer intense personal interest and recognition to students. Specific instructor behaviors in this category include: calling students by name, demonstrating excitement for their job, prompt email responses, willing to meet students outside of class, getting all students involved in class, commitment to students' success in the class, and displaying a positive, enthusiastic attitude. Example student responses demonstrating uncommonly attentive behaviors include:

He offers several class days in which attendance is not required yet he stays the entire class period to help us with whatever we need. He is very eager to help us, as well as help us get the best grade possible and improve.

She does a great job on including everyone in the class, whether it be on a class activity or random questions throughout the lecture. 
She is very enthusiastic about what she is teaching and likes doing her job. [She] has taken time to know us on a first name basis and takes time to answer every question, no matter how small.

Uncommonly attentive behaviors were mentioned 133 times and accounted for $25.9 \%$ of all rapport building and maintaining behaviors, making them the most frequently mentioned type of behavior.

\section{Connecting Behaviors}

Connecting behaviors were mentioned 122 times by participants and accounted for $23.7 \%$ of the rapport building behaviors. Connecting behaviors include references to humor, pleasant conversation, and friendly interaction. Responses in this category describe instructors as funny, easy going, approachable, informal, calm and collected. Telling jokes, making students feel comfortable, and not intimidating students all demonstrated connecting behaviors. Example student responses of connecting behaviors include:

He talks informally which helps make the students more comfortable speaking up in class... he is a fun person, which positively connects him with everyone.

He is really laid back when talking to us... and he'll make jokes and stuff that make us laugh and feel comfortable.

My instructor is very casual in the way she leads the class, and the atmosphere is relaxing.

He incorporates jokes and humor into his lessons that makes them more enjoyable and more interesting to listen to.

\section{Information Sharing Behaviors}

Information sharing behaviors accounted for $106(20.6 \%)$ of total rapport behaviors. Information sharing behaviors include dimensions of instructor credibility and clear communication with students. Instructors who demonstrate information sharing behavior give advice, impart knowledge, and communicate clear expectations regarding student work. Students' descriptions of instructors as intelligent, experts, and challenging were included in this category. Supportive nonverbal communication behaviors including instructors smiling, nodding and making eye contact with students were also included in the information-sharing category. Example student responses describing information sharing behaviors include:

When students are giving speeches he smiles and nods throughout as though he is following along with what we are saying, instead of jotting down notes the entire time.

When it comes to grades, all marks are commented upon so that the grade is fair. We, as students, know what is expected of us and therefore know how to obtain the grade we want.

He gives good examples and show video clips; all of his points seem valid. He comes prepared in the sense that he knows what he wants to lecture about beforehand, and he makes it quick and painless.

She speaks with confidence and uses examples that prove credibility. 


\section{Courteous Behaviors}

Courteous behaviors display honesty, empathy, and respect to students. These behaviors were mentioned 97 times by participants $(18.9 \%$ of total). Responses in this category describe instructors as flexible, supportive, inclusive, consistent, fair, and willing to listen. Instructors who demonstrate courteous behaviors are described as being open to questions, trusting students, understanding, and creating an environment where students feel they can speak openly. Examples of responses describing courteous behaviors include:

He listens to what I say and respects everyone's opinions.

I feel she does aim to create an atmosphere of trust throughout the classroom, which makes it [easier] to speak in front of my peers.

He listens to our contributions and tries to respond to them specifically. Everyone's ideas and questions are respect[ed] and answered.

\section{Common Grounding Behaviors}

Common grounding behaviors were mentioned the least, with $56(10.9 \%)$ responses mentioning rapport building behaviors in this category. Common grounding behaviors occur when instructors speak on the student's level and find similarities with students. Student comments in this category typically describe instructors who are personable, relate to students, are down to earth, and not condescending. Responses describing common grounding behaviors include:

She talks about things that pertain to us. She clearly understands the life of an undergraduate student.

He is very personable and easy to talk to.

They show that they understand out class and our issues as a college student.

He uses a lot of things that relate to people our age and makes us feel incorporated with the material. He is also young so that makes it easy to connect with him.

\section{Rapport Hindering Behaviors}

Although participants were asked exclusively about behaviors that build rapport, several students described specific instructor behaviors that hindered rapport. These ranged from vague dissatisfaction to detailed accounts of behaviors or specific incidents that hurt the development of instructor-student rapport. Students mentioned instructors who fail to learn student's names and do not share similar interests with students as hindering rapport. Additionally, instructors who are inconsistent and not responsive to student questions fail to build rapport. Examples of rapport hindering behaviors included:

I feel that the rapport is okay in class. Our teacher gets angry easily but he is also very nice at times. He is a little tricky to understand.

While I do respect my public speaking instructor, she has not built rapport with me because we do not share similar interests. She is very into science fiction, video games, and does not like going outside and this is the opposite of me. I like an active life and don't really like video games. Thus our interaction is nothing more than a [teacher] and student. 
I don't feel like my instructor [built] any rapport with me or the other students enrolled in the class. He missed six classes of a Tuesday/Thursday section. His lectures rarely pertained to what was actually in the book. Instead he told complicated "debate team" lectures that only slightly related to the readings, which we never discussed in class. He changed assignment due dates on short notice.

These responses are certainly important to consider, as students provided examples of rapport hindering behaviors without being prompted. While the responses indicating a lack of rapport were not coded or included in the overall analysis, these behaviors are clearly viewed differently than the behaviors described in the rapport building categories above and should be examined more closely in future research.

\section{Discussion}

The current study examined how instructors at a large Midwestern university build rapport with undergraduate students. The research question driving the study was, "What specific instructor behaviors do students view as building rapport in the classroom?" To answer this research question, 230 undergraduate students completed a survey about their public speaking instructors. Data were deductively coded using a thematic framework from a prior study (Gremler \& Gwinner, 2008). Data analysis yielded a total of 514 rapport-building behaviors, which aligned with the five themes provided by Gremler and Gwinner (2008). Implications of themes found in the data, in order of their prevalence, are briefly noted with practical implications for instructors to consider. In addition, participant responses are discussed in relation to learning outcomes. Limitations of the study and future research are also discussed.

\section{Rapport Building (and Hindering) Behaviors}

How does an instructor build rapport with undergraduate students? According to the current study, there are many ways this can occur. These behaviors, organized into five different themes, provide practical insight into how rapport building can occur in the classroom. The five themes are: uncommonly attentive behaviors, connecting behaviors, information sharing behaviors, courteous behaviors, and common grounding behaviors. Rapport hindering behaviors are also discussed.

The study's participants most often mentioned uncommonly attentive behaviors in their responses to survey questions about building rapport. This finding provides valuable insight into the importance of putting effort into treating students as individuals, as opposed to simply seeing students in the collective sense. These behaviors will, no doubt, produce extra work for instructors, but can pay dividends in the long run with a positive classroom environment and potentially increased student learning.

Connecting behaviors were mentioned the second most frequently by participants. These behaviors closely align with past research on similar behaviors, such as humor (e.g. Gorham \& Christophel, 1990) and immediacy (e.g. Frymier \& Houser, 2000). It is clear that participants feel a need to have a personal connection with their instructors for mutual trust and harmony to occur. This finding calls instructors to move beyond simply providing rote knowledge to students and to connect with students on an interpersonal level.

The third most often mentioned behaviors were information sharing behaviors. This finding supports past research that behaviors such as clarity can enhance learning (e.g. Chesebro 
\& McCroskey, 1998). Participants in the study wanted to have clear expectations and feedback from instructors. This finding has implications for instructors to make a serious effort in areas such as syllabus design, feedback for assignments, and even nonverbal responses to classroom discussion. In short, students want to know what to expect in their classes and want to know where they stand, in regard to the class.

Participants mentioned courteous behaviors $18.9 \%$ of the time in their responses. Students regularly mentioned that they needed to feel safe and understood by their instructors. This finding provides practical implications for how instructors deal with behavioral issues in the classroom, how they facilitate classroom discussion, and how instructors handle student absences. The findings do not imply that instructors should let students walk all over them, but instead it suggests that students feel rapport with instructors when instructors treat them with a level of compassion and respect.

Common grounding behaviors were only mentioned $10.9 \%$ of the time, making it the least noted type of behavior. This finding should come as a relief to instructors who might feel a pressure to be "cool" or to be friends with students. Participants valued behaviors such as providing clear expectations and providing personal, timely feedback at a much higher rate than common grounding behaviors. This finding suggests that although some students want their instructors to speak to them at the student's level, there are other more effective ways for instructors to build rapport with students.

The rapport-hindering behaviors mentioned in the study provide valuable advice for instructors on what to avoid in the classroom. Although participants were not explicitly asked what hurts instructor-student rapport, several felt justified to mentioned behaviors that would hinder rapport. This finding does two things. First, it shows that rapport can potentially be lost just as easily as it can be built with students, thus providing an opportunity for training on what not to do in the classroom in regard to interpersonal relationships. Second, this accidental finding provides opportunities for future research specifically on behaviors to avoid with undergraduate students.

Both the rapport-building and rapport-hindering behaviors discovered in this study have practical implications for college instructors at any level and can provide useful information for training and the evaluation of instructors. Although rapport building is certainly not the only criteria for teaching effectiveness, the positive outcomes of rapport have been consistently demonstrated (e.g. Frisby \& Martin, 2010). The specific behaviors found in this study can be offered as suggestions for beginning instructors on how to develop rapport. By providing examples of how to build rapport with students, new instructors will be able to implement these specific behaviors early in their teaching career. Experienced instructors can also benefit from this research, for both reflection and evaluation purposes. The findings of this study could certainly be added to graduate student teaching training and evaluation, as well.

\section{Effects of Rapport Building}

For the current study, specific conclusions are not drawn regarding the causality of learning outcomes associated with the use of each type of rapport-building behavior. Other studies have shown positive learning outcomes to be associated with rapport building (e.g., Schrodt and Witt, 2006; Frisby and Myers, 2008; \& Roach et al., 2005). The results of this study provide qualitative support to past research on rapport building, by showing that there is a perceived connection with instructor-student rapport and learning outcomes. Several participants 
highlighted the connection between rapport and learning, by providing their personal evaluations of how rapport-building behaviors influences the classroom environment and positive feelings towards the course and instructor:

My instructor gives the class positive mutual attention and has a great personal connection with everyone. The instructor makes class very enjoyable. The instructor is GREAT.

I like that my teacher makes jokes, and never says really negative things in front of the class about how we did with our speeches. And even just if we are doing little exercises he always points out the positives, which makes it easier to feel comfortable going in front of the class

I feel very connected to my instructor. He really can compare to everyone in the class, has a great sense of humor and seemingly, quite a bit in common with me personally. He encourages verbal participation and really gets a great response because of his personality. I consider his class my favorite of the semester.

These comments support the existing research on positive benefits of instructor-student rapport and demonstrate a few ways that specific rapport behaviors can enhance the classroom environment. It is clear that specific instructor behaviors such as uncommonly attentive behavior, common grounding behavior, courteous behavior, connecting behavior, and information sharing behavior can enhance the student experience. While claims cannot be made regarding the effectiveness of each specific category of behavior, the findings here demonstrate that students value rapport building behaviors, especially uncommonly attentive behaviors and connecting behaviors, in the classroom.

On a related note, the current research also adds to the body of literature on the Affective Learning Model (Rodriguez et. al, 1996), which seeks to explain how instructor behaviors can affect student learning. Much of the prior research incorporating the ALM has used quantitative research methods. This study, however, provides an additional layer of analysis to ALM. The study strengthens the claims of the model by giving a voice to college students on the subject of instructor-student rapport and providing concrete examples of rapport-building behaviors. These behaviors, as seen through the lens of ALM, influence instructor-student relationships, which can also potentially promote affective and cognitive learning.

\section{Limitations and Future Research}

Students in this study reported on the rapport behaviors of their public speaking course instructor, which is different from other recent studies on instructor-student relationships. Other studies (e.g. Sidelinger, 2010) have followed a methodology utilized by Plax, Kearney, McCroskey, and Richmond (1986) that recommends students report on the instructor they had in their class prior to completing a survey on instructor-student relationships. This methodology is used to ensure diversity among instructors, subject areas, and classroom experiences (Frisby \& Martin, 2010). The current study took the opposite approach and studied rapport in a specific instructional setting, the public speaking classroom, to provide a more controlled environment as a point of comparison. The rapport building behaviors described by students in this study may not necessarily generalize to other classroom settings, and further research is needed to determine if students report similar rapport behaviors in other types of courses.

Studying instructor-student rapport in public speaking classes in a large university setting has implications for guiding future research in other educational settings. Future research could 
include studying instructor-student rapport in liberal arts universities, online classrooms, other subject areas, and intercultural educational settings, among others. The methodology of this study to examine instructor-student rapport in one specific general education setting can provide a point of comparison for rapport building in other educational contexts.

Additionally, all of the participants in this study were enrolled in a public speaking class taught by a graduate teaching assistant or part-time lecturer, which means that none of the participants reported on rapport building with a full-time faculty member. Although participants were not asked to report the age or experience level of their instructor, many graduate teaching assistants in the department studied are relatively close in age to the undergraduate student population, which may make it easier to build instructor-student rapport. For example, one participant stated:

My teacher is younger, which automatically makes him easier to relate to as a student.

Instructor-student rapport, specifically in the area of common grounding behaviors, may look different when the instructor is a tenured-faculty member, rather than a graduate student. However, a growing number of graduate teaching assistants serve as instructors and could use the findings from this study to assist them as they begin their teaching career. Based on United States Department of Labor (2010) data, there are 108,000 graduate assistants employed in American universities, demonstrating the increasing frequency with which undergraduate students are taught by graduate teaching assistants. Further research is needed to examine rapport with different ranks of instructors.

Also, although the self-administered survey has many advantages, this method of data collection is not perfect. Since students had no supervision, they may not have taken the survey seriously, and thus may rush through the survey simply to get credit for completing it. Also, since students could take the survey wherever and whenever, there is no way for controlling the outside factors may influence students while taking the survey. Future research could include interview data to still allow for qualitative inquiry, while limiting potential distractions.

\section{Conclusion}

Studies have consistently demonstrated the positive learning outcomes associated with instructor-student rapport. This research extends previous findings by offering insight on specific instructor behaviors that students describe as building rapport in the classroom. These behaviors provide practical guidelines for instructors on how to build rapport with students, and, on the other hand, behaviors to avoid.

Interpersonal communication is vital to student learning and building rapport has been shown to be an effective way of communicating with students. By engaging in uncommonly attentive behaviors, connecting behaviors, information sharing behaviors, courteous behaviors, and common grounding behaviors, instructors will hopefully experience improved instructorstudent relationships, which will lead to more effective teaching, and, ultimately, improved student learning. 


\section{References}

Bloom, B. S., \& Krathwohl, D. R. (1956). Taxonomy of Educational Objectives: The Classification of Educational Goals, by a Committee of College and University Examiners. New York: Longmans.

Brookfield, S. D. (1995). Becoming a Critically Reflective Teacher. San Francisco, CA: JosseyBass.

Catt, S., Miller, D., \& Schallenkamp, K. (2007). You are the Key: Communicate for Learning Effectiveness. Education, 127, 369-377.

Chesebro, J. L., \& McCroskey, J. C. (1998). The Relationship between Teacher Clarity and Immediacy and Students' Experiences of State Receiver Apprehension when Listening to Teachers. Communication Quarterly, 46, 446-455. doi: 10.1080/01463379809370114

Dobransky, N., \& Frymier, A. (2004). Developing Teacher-Student Relationships through out of Class Communication. Communication Quarterly, 52, 211-223. doi:

$10.1080 / 01463370409370193$

Faranda, W. T., \& Clarke, I. (2004). Student Observation of Outstanding Teaching: Implications for Marketing Educators. Journal of Marketing Education, 26, 271-281.

Flanagan, J. C. (1949). Critical Requirements: A New Approach to Employee Evaluation. Personnel Psychology, 2, 419-425. doi: 10.1111/j.1744-6570.1959.tb01413.x

Flanagan, J. C. (1954). The Critical Incident Technique. The Psychological Bulletin, 51, 327-358. doi: $10.1037 / \mathrm{h} 0061470$

Frisby, B. N., \& Martin, M. (2010). Instructor-Student and Student-Student Rapport in the Classroom. Communication Education, 59, 146-164.

Frisby, B. N., \& Myers, S. A. (2008). The Relationships among Perceived Instructor Rapport, Student Participation, and Student Learning Outcomes. Texas Speech Communication Journal, $33,27-34$

Frymier, A. B., \& Houser, M. L. (2000). The Teacher-Student Relationship as an Interpersonal Relationship. Communication Education, 49, 207-219. doi: 10.1080/03634520009379209

George, David (2007). Market Overreach: The Student as Customer. The Journal of SocioEconomics, 36, 965-977. doi: 10.1016/j.socec.2007.01.025

Gorham, J., \& Christophel, D. M. (1990). The Relationship of Teachers' Use of Humor in the Classroom to Immediacy and Student Learning. Communication Education, 39, 46-62. doi: $10.1080 / 03634529009378786$ 
Gremler, D. D. (2004). The Critical Incident Technique in Service Research. Journal of Service Research, 7, 65-89. doi: 10.1177/1094670504266138

Gremler, D. D., \& Gwinner, K. P. (2000). Customer-employee rapport in service relationships. Journal of Service Research, 3, 82-104. doi: 10.1177/109467050031006

Gremler, D. D., \& Gwinner, K. P. (2008), Rapport-building Behaviors Used by Retail Employees. Journal of Retailing, 84, 308-324. doi: 10.1016/j.jretai.2008.07.001

Hughes, H. (2007) Critical Incident Technique. In Lipu, Suzanne, Williamson, Kirsty, \& Lloyd, Annemaree (Eds.) Exploring Methods in Information Literacy Research (pp. 49-66). Charles Sturt University, Wagga Wagga, N.S.W: Centre for Information Studies.

Kain, D. L. (1997). Critical Incidents in Teacher Collaboration on Interdisciplinary Teams. Research in Middle Level Education Quarterly, 21, 1-9.

Mazer, J. P., Murphy, R. E., \& Simonds, C. J. (2007). I'll See You on "Facebook": The Effects of Computer-mediated Teacher Self-disclosure on Student Motivation, Affective Learning, and Classroom Climate. Communication Education, 56, 1-17. doi: 10.1080/03634520601009710

McLaughlin, M. L., \& Erickson, K. V. (1981). A Multidimensional Scaling Analysis of the "Ideal Interpersonal Communication Instructor." Communication Education, 30, 393-398. doi: $10.1080 / 03634528109378494$

Nadler, J. (2007). Build Rapport--and a Better Deal. Negotiation, 3, 9-11.

Nguyen, H. T. (2007). Rapport Building in Language Instruction: A Microanalysis of the Multiple Resources in Teacher Talk. Language \& Education: An International Journal, 21, 284303. doi: $10.2167 / 1 \mathrm{e} 658.0$

Philan, L. (2012). Interrogating Students' Perceptions of their Online Learning Experiences with Brookfield's Critical Incident Questionnaire. Distance Education, 33, 31-44. doi: 10.1080/01587919.2012.667958

Plax, T. G., Kearney, P., McCroskey, J. C., \& Richmond, V. P. (1986). Power in the Classroom VI: Verbal Control Strategies, Nonverbal Immediacy, and Affective Learning. Communication Education, 35, 43-55. doi: 10.1080/03634528609388318

Roach, K. D., Cornett-DeVito, M. M., \& DeVito, R. (2005). A Cross-cultural Comparison of Instructor Communication in American and French Classrooms. Communication Quarterly, 53, 87-107. doi: 10.1080/01463370500056127

Rodriguez, J. I., Plax, T. G., \& Kearney, P. (1996). Clarifying the Relationship between Teacher Nonverbal Immediacy and Student Cognitive Learning: Affective Learning as the Central Causal Mediator. Communication Education, 45, 293-305. doi: 10.1080/03634529609379059 
Schrodt, P., \& Witt, P. (2006). Students' Attributions of Instructor Credibility as a Function of Students' Expectations of Instructional Technology Use and Nonverbal Immediacy.

Communication Education, 55, 1-20. doi: 10.1080/03634520500343335

Sidelinger, R. (2010). College Student Involvement: An Examination of Student Characteristics and Perceived Instructor Communication Behaviors in the Classroom. Communication Studies, 61, 87-103. doi: 10.1080/10510970903400311

Tsui, A. (1996) Reticence and Anxiety in Second Language Learning. In K. Bailey, D. Nunan, and M. Swan (Eds.) Voices From the Language Classroom: Qualitative Research in Second Language Education (pp. 145-167). Cambridge: Cambridge University Press.

United States Department of Labor (2010, May). Occupational Employment and Wages: 251191 Graduate Teaching Assistants. Retrieved from

http://www.bls.gov/oes/current/oes251191.htm

Worley, D., Titsworth, S., Worley, D., \& Cornett-DeVito, M. (2007). Instructional Communication Competence: Lessons Learned from Award-Winning Teachers. Communication Studies, 58, 207-222. doi: 10.1080/10510970701341170 